DR. JENNIFER CONWAY (Orcid ID : 0000-0003-4051-2185)

DR. LARA DANZIGER-ISAKOV (Orcid ID : 0000-0002-5691-5221)

RYAN ROBERT DAVIES (Orcid ID : 0000-0003-4631-9685)

DR. ANNE I DIPCHAND (Orcid ID : 0000-0001-6323-7222)

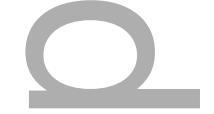

Article type : Literature Review

\title{
Part HI: Review of the Impact of Donor Characteristics on Pediatric Heart Transplant Outcomes

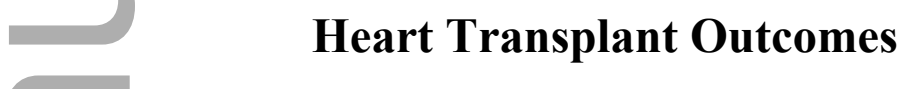

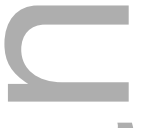

Jennifer Conway ${ }^{1}$, Jean A. Ballweg ${ }^{2}$, Matthew Fenton ${ }^{3}$, Steve Kindel ${ }^{4}$, Maryanne Chrisant $^{5}$, Robert G. Weintraub ${ }^{6}$, Lara Danziger-Isakov ${ }^{7}$, Richard Kirk ${ }^{8}$, Oliver Miera $^{9}$, Ryan R Davies ${ }^{10}$, Anne I Dipchand ${ }^{11}$

${ }^{1}$ Department of Pediatrics, Division of Pediatric Cardiology, Stollery Children's Hospital, University of Alberta, Edmonton, AB, Canada

${ }^{2}$ Department of Pediatrics, Division of Pediatric Cardiology Children's Hospital and Medical Center University of Nebraska Medical Center Omaha, NE

${ }^{3}$ Great Ormond Street Hospital for Children Foundation Trust, London, UK.

${ }^{4}$ Division of Pediatric Cardiology, Department of Pediatrics, Medical College of

Wisconsin and Herma Heart Institute and Children's Hospital of Wisconsin, Milwaukee, Wis.

5 The Heart Institute, Joe Dimaggio Children's Hospital, Hollywood, Florida

This is the author manuscript accepted for publication and has undergone full peer review but has not been through the copyediting, typesetting, pagination and proofreading process, which may lead to differences between this version and the Version of Record. Please cite this article as doi: 10.1111/PETR.13680

This article is protected by copyright. All rights reserved 
${ }^{6}$ Department of Paediatrics, The University of Melbourne; Department of

Cardiology, The Royal Children's Hospital, Melbourne Heart Research Group,

Murdoch Children's Research Institute, Melbourne, Australia

${ }^{7}$ Pediatric Infectious Diseases, Cincinnati Children's Hospital Medical Center \&

University of Cincinnati, Cincinnati, $\mathrm{OH}$.

${ }^{8}$ Division of Pediatric Cardiology, University of Texas Southwestern Medical Center,

Children's Medical Center, Dallas, Texas, USA

${ }^{9}$ Department of Congenital Heart Disease/Pediatric Cardiology, Deutsches

Herzzentrum, Berlin, Germany

${ }^{10}$ Department of Cardiovascular and Thoracic Surgery, University of Texas

Southwestern Medical Center, Children's Medical Center, Dallas, Texas, USA.

${ }^{11}$ Labatt Family Heart Centre, Hospital for Sick Children, University of Toronto,

Toronto, Ontario, Canada

\section{Corresponding Author:}

Jennifer Conway

8440112 Street, WMC 4C2

Edmonton, AB, Canada

T6G2B7

Email: Jennifer.conway2@ahs.ca

Phone: 780-407-8361

Fax: 780-407-3310

Running Title: Donor Co-morbidities

Keywords: Pediatric, Heart Transplant, Donor, comorbidities, outcomes

Abbreviations:

HTx: heart transplantation

HIV: Human immunodeficiency virus

ISHLT: International Society of Heart and Lung Transplantation

DRWR: donor recipient weight ratio

PVR: pulmonary vascular resistance

OPTN: Organ Procurement and Transplantation Network

DCM: Dilated cardiomyopathy 
DRHR: donor recipient height ratio

UNOS: United Network for Organ Sharing

CT: computerized tomography

MRI: Magnetic resonance imaging

CAV: cardiac allograft vasculopathy

ABO-I: ABO incompatible

PTLD: Post-transplant lymphoproliferative disorder

HLA: human leukocyte antigen

AMR: antibody mediated rejection

SRTR: Scientific Registry of Transplant Recipients

HBV: Hepatitis B virus

HCV: Hepatitis $C$ virus

NAT: Nucleic acid test

HBsAB: Hepatitis B surface antibody

HBsAg: Hepatitis B surface antigen

HBcAB: Hepatitis C antibody

HBIG: Hepatitis B immunoglobulin

HTLV-1: Human T-Lymphotropic Virus Type 1

D: Donor

R: Recipient

MDR: multi-drug resistant

TB: Mycobacterium tuberculosis

\section{Contributions:}

Jennifer Conway: writer, editing, manuscript preparation

Jean A. Ballweg: section writer and editing

Matthew Fenton: section writer and editing

Steve Kindel: section writer and editing

Maryanne Chrisant: section writer and editing

Robert G. Weintraub: section writer and editing

Lara Danziger-Isakov: section writer and editing

Richard Kirk: concept design and editing

Oliver Miera: concept design and editing

This article is protected by copyright. All rights reserved 
Ryan R Davies: concept design and editing

Anne I Dipchand: concept design and editing

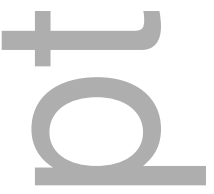

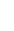

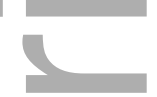

ABSTRACT

Background:

Heart transplantation (HTx) is a treatment option for end-stage heart failure in children. HTx is limited by the availability and acceptability of donor hearts. Refusal of donor hearts has been reported to be common with reasons for refusal including pre-existing donor characteristics. This review will focus on the impact of donor characteristics and comorbidities on outcomes following pediatric HTx.

\section{Methods:}

A literature review was performed to identify articles on donor characteristics and comorbidities and pediatric HTx outcomes.

\section{Results:}

There are many factors to consider when accepting a donor heart. Weight based matching is the most common form of matching in pediatric HTx with a donor recipient weight ratio between 0.7 and 3 having limited impact on outcomes. From an age perspective, donors $<50$ years, can be carefully considered but the impact of ischemic time needs to be understood. To increase the donor pool, with minimal impact on outcomes, ABO-incompatible donors should be considered in patients that are eligible. Other factors to be considered when accepting an organ include donor comorbidities. Little is known about this in the pediatric population, with most of the data focusing on infections. Being aware of the potential infections in the donor, understand testing available and risks of transmission, as well as treatment options for the recipient is essential. 


\section{Conclusions:}

There are a number of donor characteristics that potentially impact outcomes following pediatric HTx but these need to be taken into along with their interactions with recipient factors when interpreting the outcomes following HTx.

\section{INTRODUCTION}

Heart transplantation remains an important treatment strategy for end-stage heart failure in children. Unlike mechanical therapies, transplantation is limited by both the availability and acceptability of donor hearts. Refusal of donor hearts in pediatrics has been reported to be common ${ }^{1,2}$. Reasons for refusal vary with pre-existing donor characteristics potentially playing a role. The impact of donor characteristics, many of which are non-modifiable, on both short and long-term outcomes has been the focus of a number of studies. However, the understanding of the impact of donor characteristics and comorbidities on pediatric heart transplant remains limited due to multiple factors including small cohorts, lack of randomized control trials, and the global challenges of studying donor characteristics. Due to these issues the majority of data available for review is predominantly single center retrospective cohort studies intermingling with retrospective database analyses and case reports. In this section we will explore the impact of donor demographics, co-morbidities and infections on outcomes post-transplant, recognizing that outcomes cannot be solely attributed to these factors but must take into account recipient and donor-recipient interactions.

\section{METHODS}

A literature search was performed in Medline database in October 2018, including the MESH Headings: 'Tissue Donor', 'Heart Transplantation', 'Heart', 'Transplant', 'infant', 'child' , 'adolescent' along with the following terms: donor, Cardiac, graft, Child or variation of child. The search was limited to the English Language, humans and year greater than 2010. After removing duplicates 500 articles remained $(n=500)$. These articles were screened by two authors for relevance to the subjects within the review $(n=95)$. These articles were than further reviewed by each of the section authors before incorporating them into 
the written review. In addition, a second review was performed in Medline, EMBASE, PubMed and Cochrane Database in October 2018 that focused on infection issues, the same search terms as above but not limited to children. In addition, these terms were combined with Hepatitis, HIV, Toxoplasmosis, Parasitic Disease, Tuberculosis, Bacterial infections, encephalitis, anti-bacterial agents and variations of the term infection. This resulted in 1987 articles with 446 removed due to duplications, leaving 1541, which were screened for relevance.

\section{DONOR DEMOGRAPHICS}

\section{Size matching}

Donor selection for heart transplant recipients is a process involving complex matching of both donor and recipient characteristics. Of these characteristics, determining the appropriate size donor heart depends on a complex web of interactions that needs to be analyzed rapidly at the time of an offer.

The International Society of Heart and Lung Transplantation (ISHLT) guideline for care of the heart transplant recipient suggests a donor recipient weight ratio (DRWR) between 0.7 and 2.0 , for those that are sex matched or male to female. In the case of female to male heart transplantation the DRWR suggestion was increased to 0.8 and $2.0 .^{3}$. These guidelines may not necessarily apply to children given the wide range of patients and complexities that are encountered in pediatrics.

Finding the optimal size match is essential to maximize the chances of finding a suitable organ whilst limiting exposures to serious complications while waiting for transplant. The failure to accept a donor organ with a DRWR greater than 2.0, for instance, may lead to a child waiting longer, experiencing complications and in turn resulting in a worse overall outcome. For this reason, many pediatric centers around the world have modified the criteria for DRWR to include ratios outside the above ISHLT guidelines.

Several studies in children have addressed outcomes in relation to DRWR. Extending the DRWR upwards to 3.0 has been reported to be safe. Kanani et al. divided the 
DRWR into three tertiles, comparing a number of different factors between tertiles ${ }^{4}$. An increased DRWR did not significantly increase the incidence of right heart failure, length of intubation or length of stay. Within this study there were 9 children with a DRWR $>3$. There was no difference between these patients and the rest of the group with respect to mortality, hypertension, right heart failure or time to discharge following transplant. These results suggest that stretching the DRWR upwards can be associated with acceptable results. Similar results have also been reported supporting a DRWR upper value of $2.0^{4}$.

A review of the UNOS database of 3048 pediatric recipients examined the lower end of the DRWR range and reported no difference in outcomes with a DRWR above 0.6 compared to recipients with a DRWR of $\geq 0.8$. Thirty-day mortality was significantly increased when the DRWR fell below 0.6, which is helpful when considering the lower threshold for acceptance ${ }^{5}$. Despite these size mismatches it is reassuring that growth and remodeling of the transplanted heart does occur over time with respect to the cardiac dimensions and myocardial mass ${ }^{6}$. Undersizing of donors has also been raised as a potential concern in adults. Taghavi et al. in a single center study, report the safety of using a DRWR down to 0.7 in adults ${ }^{7}$. There was no difference in outcome for patients following female into male transplants but they did note that the expected resolution of raised PVR after transplant was not seen when undersized donor hearts were utilized. A similar study, from 21,928 adult patients in the UNOS database, divided patients into an acceptable DRWR ( $>0.9)$, a low ratio (0.6 to 0.9) and a very low group $(<0.6){ }^{8}$. The authors identified no difference in outcome when low ratio transplants were used for sex matched or male to female transplant procedures. However, for female to male transplants, an increased mortality was observed in the low ratio group. This data suggests that extending the DRWR to 0.7 is safe, as also shown in the pediatric data, and under circumstances where transplant may need to be expedited, extending to a DRWR of 0.6 in pediatric patients might be considered.

The concern with using undersized donors in pediatric patients with elevated PVR, has been examined by Zafar et al using the UNOS database ${ }^{9}$. They identified children with a PVR greater than $3.0 \mathrm{wU} \cdot \mathrm{m}^{2}$ and divided them into three groups of DRWR; $<0.8,0.8$ to 1.2 and $>1.2$. There was no difference in survival between these 
three groups. On sub-analysis, those recipients with DCM who had an oversized donor had better outcomes than congenital heart disease patients with an oversized donors. Therefore, the practice of placing a larger heart into a patient with raised PVR, in the context of congenital heart disease needs careful reconsideration and further research to understand these findings.

It is also important to consider whether using other size related demographic data, besides weight, to match donors and recipients is superior. Height, body mass index and body surface area all have different mathematical regression curves predicting, "heart size". Patel et al. queried the OPTN database and included 2234 children who received transplants for DCM ${ }^{10}$. Children identified within the cohort were divided into three groups of donor-recipient height ratio (DRHR $(<0.87,0.87$ to $1.18,>1.18)$. The results identified an increased mortality at a year for the lowest group of DRHR. However, this effect disappeared when controlling for other confounding factors. Supported by these results and others, it does not appear that selecting suitable donor organs based on height rather than weight offers any further advantage ${ }^{10,11}$. As well as directly measurable morphometric parameters, researchers have also been interested in predicting the cardiac size of the normal "donor" population by using algorithms based on cross-sectional imaging such as CT or MRI. Studies have suggested that measuring the predicted heart mass may better predict primary graft dysfunction but not necessarily mortality ${ }^{12-14}$. No pediatric literature is available on this topic but warrants further investigation.

Other researchers have used advances in 3D reconstructions, using virtual implantation of cardiac "avatars" based on a library of expected sizes for a donor's height and weight. Whilst this demonstrates some promise, the development remains researched based and needs further refinement prior to inclusion into recommended practice ${ }^{15,16}$.

In summary, recent evidence suggests that matching by DRWR is a robust method of identifying suitable donors. The DRWR advocated by the current ISHLT guidelines are conservative and extension of the DRWR significantly above and a little below is reasonable based on appropriate risk-benefit analysis for individual recipients. Newer methods of matching based on predictive heart mass show promise, particularly for 
those recipients requiring robust cardiac output in the immediate post-transplant period.

\section{$\underline{\text { Donor Age }}$}

The ISHLT guidelines for heart transplant care states that donors under the age of 45 years are likely to have the metabolic reserve to withstand the rigors of cold transportation even with prolonged ischemic time ${ }^{3}$. In pediatric heart transplantation, the majority of donors are $\leq 18$ years of age as outlined in the ISHLT registry. Of the 7730 pediatric transplants in the ISHLT registry report $24 \%(\mathrm{n}=1841)$ were from donors older than 18 with $9 \%(n=701)$ being older than 31 years. However, there is a significant difference in the age range of donor hearts between Europe and North America. Less than $1 \%$ of donors used for pediatric recipients in North America are older than 35 years of age compared to $19 \%$ of donors in Europe ${ }^{17}$.

The ISHLT registry report has identified increasing donor age in adults as a risk factor for higher mortality at 1, 5 and 10 years post-transplant as well as a risk factor for development of CAV within 5 years post-transplant ${ }^{18}$. Reich at al investigated the effect of increasing donor age above or below 50 years and the interaction with ischemic time ${ }^{18}$. The authors divided patients by ischemic time into short $(<120$ mins), medium (120 -240) and long ( $>240)$ groups. Five-year survival was reduced in older donors who had medium and long cold ischemic times. However, mortality was no different for older donors with a short ischemic time. Increase in donor age and ischemic time still provided reasonable 5-year survival in adults, around $70 \%$ compare with $80 \%$ in those with short ischemic time. This reduction in survival is likely to compensate for the increase waitlist mortality due to the shortage of younger organs.

In children, Westbrook et al queried the UNOS database to determine the posttransplant survival of weight-matched controls with a donor age difference of more or less than 5 years ${ }^{19}$. There was a significant difference in survival in those children who received a donor organ that was $>5$ years older than their chronological age. This was particularly relevant for those recipients' ages 11-17 receiving hearts from donors who were $\geq 25$ years of age. 
In those recipients receiving a donor greater than 25 years old, mortality was significantly worse at 10 years when compared with those patients receiving a donor greater than 5 years older but $<25$ years $(60 \%$ vs. $44 \%)$ In addition, those patients receiving a donor $>5$ years older, also developed CAV earlier. Freedom from CAV at 10 years post-transplant was $72 \%$ in those with a donor age within 5 years compared to $56 \%$ in those with an older donor ${ }^{19}$.

An interesting report by Weber et al. examined a large group of adult transplant recipients receiving donor hearts aged 18-39 and compared them to older donor groups (age: $40-49,50-54$ and $\geq 55$ years) ${ }^{20}$. The authors identified increasing mortality with older donor age with a hazard ratio of 1.4 for recipients with a donor $\geq 55$ years. The authors performed propensity matching for recipients receiving donor hearts greater than 55 years with those listed with high urgency for heart transplant (status 1A). Survival was better for those patients prioritized for heart transplant even when transplanted with an older donor. However, when donor age was used as a continuous variable, it was not identified as a risk factor for either mortality or CAV. This lack of predictive value differs from studies selecting an arbitrary age threshold 21,22. In addition to survival, co-morbidities such as cerebrovascular accidents were seen more frequently in the older donor age group, potentially reflecting the state of vascular morbidity in older donors.

From the available evidence the impact of increasing donor age on post-transplant mortality and development of CAV is not universally corroborated. Comparable arbitrary age cutoffs have not been standardized and donor age as a continuous variable in multivariate analysis does not stand out from other important risk factors for recipient survival or development of CAV. It seems reasonable to conclude that increasing donor age is an important risk factor for transplant survival and using donor hearts greater than 50 years requires careful consideration of the relative risk and benefits of proceeding, as well as the logistics involved, including ensuring that ischemic times are kept short. However, it is important to consider that the differences in survival related to increasing donor age may be outweighed by the mortality seen in children who are waiting for transplant and would benefit from widening the donor pool through the use of older donors.

\section{$\underline{\mathrm{ABO}-\mathrm{I} \text { and Outcomes }}$}

This article is protected by copyright. All rights reserved 
In addition to expanding the weight range and age to potentially increase the number of donors and decrease the waitlist mortality, another strategy that has been applied to increase the donor pool for pediatric patients is the use of ABO blood group incompatible (ABO-I) donors. ABO-I infant heart transplantation was pioneered at the Hospital for Sick Children Toronto in $1996^{23}$ in an effort to overcome the obstacles in infant transplantation. This strategy was found to be favorable with a decline in the waitlist mortality from $58 \%$ in 1996 in Toronto to $7-10 \%$ after the institution of ABO-I strategy ${ }^{23-26 .}$

To date there has been no reported difference in post-transplant morbidities or graft survival between children with an ABO-I compared to those with an ABO compatible graft ${ }^{26}$. Specifically, there is no significant difference in the 5-year freedom from CAV, moderate acute cellular rejection, renal dysfunction or PTLD.

The positive outcomes reported from Toronto, have been replicated in a retrospective multi-center study of 58 ABO-incompatible transplants performed between 2001 and 2010. Freedom from death or retransplantation was $100 \%$ at one year, $96 \%$ at 5 years and $69 \%$ at 10 years 27 . Two patients underwent retransplantation; one for development of refractory hypertrophic cardiomyopathy with mitral regurgitation and the second for chronic graft failure. Two patients died in the follow up period; one due to acute multiorgan failure with systemic infection and the second due to combined cellular rejection and AMR associated with donor specific HLA antibodies and positive lymphocyte crossmatch ${ }^{27}$. Of the 13 patients who had peak antibody titers $>1: 8$ against the donor blood group, six had AMR that was treated with clinical recovery and normalization of follow up biopsies ${ }^{27}$.

Current practice defining upper age and titers does vary between institutions and countries. In the United States the acceptance of an ABO-Incompatible donor heart is outlined in a UNOS policy. This policy has recently been revised increasing the isohemagglutin titers to $\leq 1: 16$ and the child now needs to be registered before their second birthday. However, with increasing experience, in other countries were no policy exists the upper titer, upper recipient age and interaction between these two are still being defined. 
In summary, the acceptance of ABO-incompatible heart donors has become a widely used approach to increase the donor pool and potentially decrease waitlist mortality for infants and young children, without compromising post-transplant outcomes.

\section{DONOR COMORBIDITIES}

\section{Donor Comorbidities:}

In addition to donor demographics, the impact of donor comorbidities on outcomes following transplant should be considered when making decisions about donor suitability. This particular section will focus on hypertension, diabetes, anaphylaxis, neoplasia history, and genetic syndromes in the donor.

\section{Hypertension}

Currently there are no pediatric studies examining the impact of donor hypertension on cardiac transplant outcomes. While chronic donor hypertension could be postulated to impact both graft function and development of CAV, direct study of this issue is limited by the availability of donor health data and often donor cardiac hypertrophy is taken as a surrogate finding for hypertension. One recent adult single center study demonstrated that donor hypertension as assessed by a health questionnaire correlated with reduced graft survival ${ }^{28}$. A separate analysis of the impact of donor renal disease on recipient outcomes, found that donor hypertension was associated with a higher risk of retransplant or death ${ }^{29}$.

\section{Diabetes}

Donor diabetes may also be a plausible risk factor for graft failure or CAV. Again while no pediatric studies exist, a single center retrospective analysis in adults did show that carefully selected diabetic donors could be used successfully for heart transplant without increased recipient risk ${ }^{7}$. The authors further demonstrated the insulin-dependent diabetes and diabetes history greater than 5 years were not associated with worse outcomes. However, in a cohort of donors with renal disease, diabetes was found to be a risk factor for graft loss even though renal dysfunction itself was not ${ }^{29}$.

\section{Anaphylaxis}

This article is protected by copyright. All rights reserved 
Though the yearly incidence of food anaphylaxis is rare (estimated at $0.0004 \%$ of the U.S. population) ${ }^{30}$ it may be a feature present in a potential donor. There are several reports of donor peanut allergy conferred upon a solid organ recipient, dating back to $1989^{31,32}$. The onset of the acquired allergy can be weeks to months post-transplant, and can occur irrespective of age of recipient or organ type. The prominent finding is the occurrence of an anaphylactic or sensitivity reaction in response to ingesting the food, most often peanuts, though reactions to other foods have been reported. These reactions can be transient and resolve over time, however others report that these acquired food allergies remain a life-long issue ${ }^{33}$, Given this impact it may be prudent to include this in donor screening and post-transplant follow up.

\section{Neoplasia}

While a comprehensive exploration of all other donor comorbidities is not possible in this review, some other pertinent situations were considered. The presence of a donor history of oncologic disease was reviewed as a risk factor for solid organ transplantation using a retrospective review of the Scientific Registry of Transplant Recipients (SRTR) database showed no increased risk of early death or graft loss in recipients of a donor with oncologic history ${ }^{34}$. Although notably, hematologic and otolaryngotic tumors were associated with decreased recipient survival following heart transplantation ${ }^{34}$.

The overall paucity of data on this subject prompted the OPTN/ UNOS to establish a Disease Transmission Advisory Committee tasked with producing guidelines on organ acceptance from donors with a positive malignancy history. Their document recommended employing a strategy of utilizing anticipated donor malignancy recurrence-free survival or 'cure' rates as a surrogate marker for transmission risk. 'Low risk' would be expected from donors who are cancer free for at least 5 years with a cure probability of cure $>99 \%$; 'intermediate risk' would be those with a 90-99\% cure rate; and 'high risk' would be associated with incurable cancers, insufficient follow up or cure probability $<90 \%{ }^{35}$. Additional consideration should be given to the metastatic potential of the donor's current or prior malignancy. In general, however, considering the overall limited data and near absence in the pediatric population, there is insufficient 
data to make any meaningful recommendations for the pediatric donor with a history of or active malignancy.

\section{Genetics}

Finally, and pertinent specifically in pediatrics, the presence of genetic syndromes in donors has been reported in a series of two cases, one in a donor with Trisomy 21 and another with Turner Syndrome. While both transplants were reported to be a success the authors warn of increased surgical challenges that should be planned for when accepting such organs ${ }^{36}$. In addition, understanding the natural history of the genetic condition, including the potential effects on the heart are essential to avoid any long term complications.

\section{DONOR INFECTIONS}

Donor infections represent another category of donor co-morbidities that may impact transplant outcomes. This is because a variety of infections (viral, bacterial, fungal and others) can be transmitted through organ transplantation ${ }^{37}$. Transmitted infections have the potential to cause significant morbidity and mortality in solid organ transplant recipients despite donor derived transmission being reported in less than $1 \%$ of donors 38,39 . Variable rates of transmission may be due to the pathogen inoculum, the organ being transplanted and the extent of immune suppression ${ }^{38}$. Families of transplant candidates should be informed in advance that despite comprehensive screening, no individual test can fully eliminate the possibility of transmitting an infection ${ }^{40}$. International organ procurement organizations have developed definitions of "increased risk" donor to help aid in the identification of risk to the recipient at the time of transplant ${ }^{41,42}$.

The risk of transmitting HBV, HCV and HIV can be reduced by a thorough donor history combined with serological testing of the prospective donor. However, donor history may be inaccurate or incomplete, as it may come from a third party that lacks full knowledge about risk behaviors. Although donor to recipient infection can still be transmitted despite negative serology and nucleic acid testing (NAT) due to a 
"window period", the risk of HIV and HCV transmission is significantly reduced when both serology and NAT are negative ${ }^{43}$. This type of testing also potentially increases organ utilization from NAT-negative, increased-risk donors ${ }^{42}$.

\section{Hepatitis B virus}

Standard risk donors who are negative for all 3 serological tests and those who have been vaccinated identified through $\mathrm{HBs} A \mathrm{~B}$ positivity alone can be used for all recipients. Donors who are $\mathrm{HBs} A g$ negative and $\mathrm{HBcAB}$ positive may have resolving acute infection, remote infection or (rarely) occult chronic infection, or this result may also be a false positive ${ }^{44}$. NAT may be helpful and decisions about using a donor with this profile need to be made after individualized assessment of the risks and benefits, in conjunction with an expert. Heart transplant recipients who are immune

prior to transplantation are at significantly decreased risk of transmission ${ }^{44,45}$. Donors who are HBsAg positive likely have active infection. There is limited data about whether pretransplant vaccination and post-transplant HBIG with antiviral prophylaxis can prevent $\mathrm{HBV}$ transmission from $\mathrm{HBsAg}$ donor hearts. While this approach it is generally not recommended, consideration should be given to this approach in emergent settings in low prevalence areas after an individualized assessment is performed in conjunction with an expert ${ }^{44}$.

\section{Hepatitis $\mathbf{C}$ virus}

Standard risk donors who are $\mathrm{HCV}$ seronegative can be used without further testing. NAT testing should be performed in HCV AB positive donors, and a significant proportion will be negative, indicating no active infection. A very high proportion of HCV NAT positive donors will transmit infection to the recipient ${ }^{42}$. Decisions about donors who are NAT positive should be made in conjunction with an expert to consider if the recipients would be eligible for direct acting antiviral therapy to treat transmitted HCV infection. Currently, direct acting antiviral therapy for HCV is approved for children $>11$ years of age, although its efficacy has not been evaluated in pediatric heart transplant recipients of $\mathrm{HCV}$ infected donors. Data in adult heart transplant recipients to support the use of HCV NAT positive organs is emerging ${ }^{46}$. It is likely that newer antiviral agents and approval of agents for a wider spectrum of pediatric patients will modify clinical protocols in coming years. 


\section{HIV}

Currently, HIV positive donors should never be used for non-HIV positive recipients. HIV positive donors can be considered for HIV positive recipients within appropriate research programs with availability of experienced experts although this has not been evaluated in pediatric heart transplant recipients.

\section{HTLV-1}

HTLV-1 is endemic in certain populations and can be transmitted by organ transplantation. HTLV-1 screening of donors should not be undertaken due to the risk for organ wastage with high risk of false positive results, low prevalence of HTLV-1 and lack of availability of reliable testing. The value of screening donors from populations with a higher prevalence is uncertain ${ }^{45}$.

\section{Parasitic infections}

Parasitic infections have been routinely reported as donor-derived infections and identification of infected donors with appropriate empiric prophylaxis/treatment is the mainstay of management.

\section{Toxoplasmosis}

Empiric prophylaxis has been shown to decrease the risk of Toxoplasmosis in recipients receiving seropositive donor hearts ${ }^{47}$ although breakthrough infection can occur despite prophylaxis 48 . Studies differ on the impact of donor/recipient mismatching and outcome for Toxoplasmosis. In the United States, a single institution showed a trend toward increased mortality in toxoplasma donor seropositive, recipient seronegative (D+/R-) patients compared to those not at risk (D-/R-) ${ }^{49}$. However, two other large European studies reported no difference in all-cause mortality across $\mathrm{D} / \mathrm{R}$ serostatus pairs (D+/R-, D+/R+, D-/R+ and D-/R- patients) ${ }^{50,51}$. Toxoplasma seropositivity in the donor is NOT a contraindication to donor utilization in pediatric heart transplantation. If either the donor or recipient is seropositive, appropriate prophylaxis should be administered to decrease the risk of symptomatic disease.

\section{Strongyloides}


Donor derived infections from Strongyloides have been reported in adult and pediatric transplant recipients including patients following heart transplantation ${ }^{52,53}$. Initially, case reports stemmed from serious and even fatal Strongyloides infections that were identified through retrospective assessment revealing negative pre-transplant recipient serology with positive donor serology ${ }^{54}$. More recently, screening of at-risk donors has become more common allowing for identification in the donor and mitigation in the recipient with pre-emptive therapy ${ }^{55-57}$.

\section{Chagas}

Trypanosoma cruzi, the etiologic parasite causing Chagas disease, is endemic in Central and South America that can cause a chronic infection involving the heart or gastrointestinal tract. Transmission of Chagas disease from donors to recipients has been documented in solid organ transplantation and occurs more commonly in heart transplantation compared to other solid organs ${ }^{58,59}$. At least one transmission from a donor to an adolescent recipient has been documented with evidence of infection by three weeks post-transplant ${ }^{59}$. Currently, based on the increased risk for infection and associated morbidity and mortality, the WHO, Spanish and United States Consortia all advise against the use of heart donors who are seropositive for $T$. cruzi although other organs from these donors can be considered ${ }^{58-60}$.

\section{Malaria}

Plasmodium falciparum has been transmitted to an adult heart transplant recipient from a donor from an endemic country despite negative peripheral smear at the time of transplant. Retrospective serology revealed the donor had been previously infected. Treatment with erythropheresis, quinine, artesunate and atovaquone-proguanil was successful ${ }^{61}$.

\section{Bacterial infections - bacteremia, meningitis, pneumonia \& tuberculosis}

Bacterial infections occurring in potential donors complicate the decision regarding suitability of a donor for pediatric heart transplantation. Donors with a variety of infections including any culture positivity and meningitis have been reported without significant impact on outcomes in adult heart transplantation ${ }^{62,63}$. In pediatrics, only 3 proven or probable donor derived disease transmissions related to bacterial 
infections (all Staphylococcus species) were reported in over 5000 pediatric donors in the United States, and there were no deaths attributed to these transmissions ${ }^{39}$. More specifically, Amdani et al. reported on pediatric heart transplant recipients from blood culture positive donors showing there was no difference in survival or post-transplant complications with these donors compared to donors with negative blood cultures ${ }^{64}$. However, with the emergence of multi-drug resistant (MDR) organisms, transmission from donor to recipient of these difficult to treat organisms has been reported in adult heart transplantation ${ }^{65}$, although organs from donors with some MDR organisms including carbapenamase-resistant Klebsiella pneumoniae have been safely used in at least one adult heart transplant recipient with targeted peri-operative and postoperative antimicrobial administration ${ }^{66}$. To date, no pediatric reports using donors with MDR bacterial infections appear in the literature and donors with these organisms should be considered with caution focusing on the therapies available to treat a recipient should a donor-derived infection develop.

Additionally, transmission of Mycobacterium tuberculosis (TB) from a donor has been reported in adult heart transplantation ${ }^{67}$; however, medical management of the recipient prevented TB-related morbidity and mortality despite documented transmission. Review of the literature in solid organ transplantation suggests increased risk of $\mathrm{TB}$ in donors from or traveling to endemic countries, with prior latent TB infection, active tuberculosis and known socioeconomic risk factors including homelessness and incarceration ${ }^{68}$.

\section{Fungal Infections}

Fungal infections in potential donors also pose risk to recipients with significant mortality if unrecognized and untreated in the recipient post-transplant ${ }^{69}$. The mechanism of donor death must also be considered with reports of fungal infections including Scedosporium auratiacum in an adult heart recipient from a donor who drowned 70 . Very early onset $(<30$ days post-transplant) infection with Cryptococcus has been reported in two heart transplant recipients which may represent either unrecognized infection in recipient pre-transplant or in the donor ${ }^{71}$. Unrecognized infection especially in donors from regions with endemic fungi like coccidioidomycosis appears in the literature and includes pediatric heart transplant 
recipients ${ }^{72,73}$. Prophylaxis and early therapy decrease the risk for mortality of coccidioidomycosis post-transplant 74 .

\section{Other viral infections (Dengue)}

Transmission to heart transplant recipients in endemic areas has occurred with Dengue virus and West Nile Virus. At least 4 recipients including one heart transplant recipient contracted Dengue virus from two donors in Brazil ${ }^{75}$ causing clinical illness post-transplant without deaths. However, transmission of West Nile Virus from donor to recipients has been reported to cause neuroinvasive disease in up to $70 \%$ of recipients and death in $30 \%{ }^{76}$. Although donor derived infection has not yet been reported in the literature for Zika virus, a survey of donors from an endemic area indicate that $3 \%$ were positive for Zika IgG but none were positive by PCR testing 77

\section{Encephalitis \& Amebiasis}

Donors presenting with non-bacterial meningoencephalitis have been reported to transmit a variety of infections in solid organ transplant recipients not previously covered in prior sections including but not limited to Rabies and Balamuthia mandrillaris ${ }^{77-79}$. It is recommended by the Ad Hoc Disease Transmission Advisory Committee of the United Network for Organ Sharing in the United States that donors with meningoencephalitis due to a pathogen without available treatment that extreme caution be used in determining the suitability of the donor based on the events reported to this committee

(https://optn.transplant.hrsa.gov/resources/guidance/guidance-for-recognizingcentral-nervous-system-infections-in-potential-deceased-organ-donors/).

\section{Summary Statement}

There are a number of donor characteristics that potentially impact outcomes following pediatric heart transplantation. However, we acknowledge that there are many factors that may affect the potential outcomes following heart transplantation and these need to be taken into consideration along with their interactions with donor demographics and co-morbidities. The following is a list of specific considerations with respect to donor characteristics that may be considered at the time of an offer: 
1) A donor recipient weight ratio between 0.7 and 3 should be considered when assessing a donor offer

2) Donor age $<50$ years should be considered, however this needs to be assessed in the context of the ischemic time, with longer ischemic time impacting recipient survival when older donor hearts are utilized

3) ABO-I donors should be considered in patients that are eligible, as the outcomes have been shown to be equivalent to $\mathrm{ABO}-\mathrm{C}$ patients

4) Little is known about the impact of donor comorbidities on the outcomes posttransplant in children

5) It is essential to be aware of the potential infections in the donor, understand the appropriate testing required to identify an infection, have a good understanding of the potential risks of transmission from the donor to recipient and be aware of available treatment options for the recipient post -transplant before accepting an organ.

\section{Future Research}

In order to move the field forward and impact the utilization of the donor pool, future research is required to understand the impact of interactions between various donor characteristics and donor and recipient characteristic on outcomes to aide in decision making about donor acceptance. Lastly, being able to define how we can push the boundaries with ABO-I transplants has the potential to further increase utilization.

\section{References}

1. Rizwan R, Zafar F, Bryant R, et al. The Number of Refusals for Donor Organ Quality Does Not Impact Heart Transplant Outcomes in Children. Ann Thorac Surg. 2018;105(4):1223-1230. doi:10.1016/j.athoracsur.2017.10.006

2. Zafar F, Rizwan R, Lorts A, Bryant R 3rd, Tweddell JS, Chin C MD. Implications and outcomes of cardiac grafts refused by pediatric centers but transplanted by adult centers. J Thorac Cardiovasc Surg. 2017;154(2):528-536.

3. Costanzo MR, Dipchand A, Starling R, et al. The international society of heart and lung transplantation guidelines for the care of heart transplant recipients. $J$ Hear Lung Transplant. 2010;29(8):914-956. doi:10.1016/j.healun.2010.05.034

4. Kanani M, Hoskote A, Carter C, Burch M, Tsang V, Kostolny M. Increasing 
donor-recipient weight mismatch in pediatric orthotopic heart transplantation does not adversely affect outcome. Eur J Cardio-thoracic Surg.

2012;41(2):427-434. doi:10.1016/j.ejcts.2011.04.042

5. Wiley ÓJ, Sons AS, Transplantation P, et al. Low donor-to-recipient weight ratio does not negatively impact survival of pediatric heart transplant patients. 2010:741-745. doi:10.1111/j.1399-3046.2010.01300.x

6. Walter ED et al. Influence of size disparity of transplanted hearts on cardiac growth in infants and children. J Thorac Cardiovasc Surg. 143(1):168-177.

7. Taghavi S, Jayarajan SN, Wilson LM, Komaroff E, Testani JM MA. Cardiac transplantation can be safely performed using selected diabetic donors.

2014;146(2):1-12. doi:10.1016/j.jtcvs.2013.02.047.Cardiac

8. Menting AT, de Castro BO, Wijngaards-de Meij LD MW. A trial of parent training for mothers being released from incarceration and their children. J Clin Child Adolesc. 2014;43(3):381-396.

9. Zafar F, Khan MS, Bryant R, Castleberry CD, Chin C MD. Does oversizing the donors have any benefit for Pediatric Heart Transplant recipients with elevated pulmonaryvascular resistance? J Hear Lung Transplant. 2015;34(1):S36.

10. Patel A et al. Donor-recepient height ratio and outcomes in pediatric heart transplantation. Pediatr Transplant. 2016;20(5):652-657.

11. Hahn E, Zucherman WA, Chen JM, Singh RK, Addonizio LJ RM. An Echocardiographic Measurement of Superior Vena Cava to Inferior Vena Cava Distance in Patients $<20$ Years of Age With Idiopathic Dilated Cardiomyopathy. Am J Cardiol. 2014;113(8):1405-1408.

12. Zucherman WA, Richmond ME, Singh RK, Chen JM AL. Use of height and a novel echocardiographic measurement to improve size-matching for pediatric heart transplantation. J Hear Lung Transplant. 2012;31(8):896-902.

13. Gong TA, Joseph SM, Lima B et al. Donor predicted heart mass as predictor of primary graft dysfunction. J Hear Lung Transplant. 2018;37(7):826-835.

14. Sabatino M, Masetti M et al. DONOR-RECIPIENT SIZE MISMATCH AND RISK OF EARLY GRAFT DYSFUNCTION IN PATIENTS WITH PULMONARY HYPERTENSION: POTENTIAL ROLE OF MATCHING BASED ON PREDICTED HEART MASS.

15. Szugye NA, Lorts A, Zafar F, Taylor M, Morales DLS MR. Can virtual heart transplantation via 3D imaging increase themaximum acceptable donor size? $J$ 
Hear Lung Transplant. 2018.

16. Plasencia JD, Kamarianakis Y, Ryan JR, Karamlou T, Park SS, Nigro JJ E, Al. Alternative methods for virtual heart transplant-Size matching for pediatric heart transplantation with and without donor medical images available. Pediatr Transplant. 2018;22(8):e13290.

17. Rossano JW, Cherikh WS, Chambers DC, et al. The Registry of the International Society for Heart and Lung Transplantation : Twentieth Pediatric Heart Transplantation Report - 2017 ; Focus Theme : Allograft ischemic time. J Hear Lung Transplant. 2017;36(10):1060-1069. doi:10.1016/j.healun.2017.07.018

18. Reich HJ, Kobashigawa JA, Aintablian T, Ramzy D, Kittleson MM EF. Effects of Older Donor Age and Cold Ischemic Time on Long-Term Outcomes of Heart Transplantation. Texas Hear Inst J. 2018;45(1):17-22.

19. Westbrook TC, Morales DLS, Khan mS, Bryant R, Castleberry C, Chin C ZF. Interaction of older donor age and survival after weight-matched pediatric heart transplantation. J Hear Lung Transplant. 2017;36(5):554-558.

20. Weber DJ, Wang I-W, Gracon ASA, Hellman YM, Hormuth DA, Wozniak TC et al. Impact of donor age on survival after heart transplantation: an analysis of the United Network for Organ Sharing (UNOS) registry. J Card Surg United States. 2014;29(5):723-728.

21. Eskandary FA, Kohl M, Dunkler D, Aliabadi A, Grömmer M, Schiferer A et al. Lack of donor and recipient age interaction in cardiac transplantation. $J$ Hear Lung Transplant. 2014;33(6):629-635.

22. Bruschi G, Colombo T, Oliva F, Morici N, Botta L, Cannata A et al. Orthotopic heart transplantation with donors greater than or equal to 60 years of age: a single-center experience. Eur J Cardiothorac Surg Ger. 2011;40(1):e55-61.

23. West LJ, Pollock-Barziv SM DA et al. ABO-incompatible heart transplantation in infants. N Engl J Med. 2001;344:793-800.

24. Foreman C, Gruenwald C, West L. ABO-incompatible heart transplantation: A perfusion strategy. Perfusion. 2004;19(1):69-72. doi:10.1191/0267659104pf708oa

25. Bennett NJ, Tabarani CM, Bartholoma NM, et al. Unrecognized viral respiratory tract infections in premature infants during their birth 
hospitalization: A prospective surveillance study in two neonatal intensive care units. J Pediatr. 2012;161(5):814-818.e3. doi:10.1016/j.jpeds.2012.05.001

26. Dipchand AI, West LJ, McCrindle BW, Manlhiot C, Pollock BarZiv SM, VanderVliet M. Equivalent Outcomes for Pediatric Heart Transplantation Recipients: ABO-Blood Group Incompatible versus ABO-Compatible. Am J Transplant. 2010;10(2):389-397. doi:10.1111/j.1600-6143.2009.02934.x

27. Urschel S, Larsen IM, Kirk R, et al. ABO-incompatible heart transplantation in early childhood: An international multicenter study of clinical experiences and limits. J Hear Lung Transplant. 2013;32(3):285-292.

doi:10.1016/j.healun.2012.11.022

28. Guihaire J, Noly PE, Martin A, et al. Impact of donor comorbidities on heart transplant outcomes in the modern era. 2017;24(February):898-904. doi:10.1093/icvts/ivx014

29. Laur O, Brisco MA, Kula AJ, Cheng SJ, Mangi AA BL et al. The Impact of Donor and Recipient Renal Dysfunction on Cardiac Allograft Survival :

Insights into Reno-Cardiac. 2016;22(5):368-375. doi:10.1016/j.cardfail.2015.11.009.Author

30. Neugut AI, Ghatak AT MR. Anaphylaxis in the United States: an investigation into its epidemiology. Arch Intern Med. 2001;161:15-21.

31. Odish A, Chen M, Kim A FT. Acquired Donor Peanut Allergy From Lung Transplantation Resulting in Respiratory Failure: A Case Report. Transpl Proc. 2018;50(10):4085-4086.

32. Word C, Klaffky E, Ortiz C, Palacios T, Pelletier S, Oliveira W, Greb B, Workman L, Platts-Mills T WJ. Management of acquired peanut allergy following solid-organ transplant. J Allergy Clin Immunol Pr. 2015;3(4):612614.

33. Hosakoppal SS BP. Transplant Acquired food allergy: current perspectives. $J$ Asthma Allergy. 2017;10:307-315.

34. Huang S, Tang Y, Zhu Z, Yang J, Zhang Z, Wang L, Sun C, Zhang Y, Zhao Q, Chen M, Wu L, Wang D, Ju W, Guo Z HX. Outcomes of Organ Transplantation from Donors with a Cancer History. Med Sci Monit. 2018;18(24):997-1007. doi:10.12659/MSM.909059

35. Nalesnik MA, Woodle ES, Dimaio JM, et al. Donor-transmitted malignancies in organ transplantation: Assessment of clinical risk. Am J Transplant. 
2011;11(6):1140-1147. doi:10.1111/j.1600-6143.2011.03565.x

36. Gambino A, Torregrossa G, Feltrin G, Toscano G GG. Heart donors with underlying genetic syndromes. J Hear Lung Transplant. 2010;29(5):588-589.

37. Ison MG NM. An update on donor-derived disease transmission in organ transplantation. Am J Transpl. 2011;11:1123-1130.

38. Ison MG, Llatac E CC et al. Transmission of Human Immunodeficiency Virus and Hepatitis C Virus From an Organ Donor to Four Transplant Recipients. Am J Transplant. 2011;11:1218-1225.

39. Green M, Covington S, Taranto S, Michaels MG, Wolfe C, Kaul DR. Pediatrics and donor-derived disease transmission: The US OPTN experience. Pediatr Transplant. 2018;22(1):1-5. doi:10.1111/petr.13115

40. Seem DL, Lee I, Umscheid CA KM. Excerpt From PHS Guideline for Reducing HIV, HBV and HCV Transmission Through Organ Transplantation. Am J Transplant. 2013;13:1953-1962.

41. Seem DL, Lee I, Umscheid CA et al. United States Public Health Service: PHS guideline for reducing human immunodeficiency virus, hepatitis B virus, and hepatitis $\mathrm{C}$ virus transmission through organ transplantation. Public Heal Rep. 2013;128:247-343.

42. Humar A, Morris M, Blumberg E. Nucleic Acid Testing ( NAT ) of Organ Donors: Is the ' Best' Test the Right Test? A Consensus Conference Report. Am J TransplantJ Transpl. 2010;10:889-899. doi:10.1111/j.16006143.2009.02992.x

43. Ison MG. Nucleic Acid Testing of Organ Donors : Is the Glass Half Empty or Half Full ? Am J Transpl. 2015;15(3):1743-1745. doi:10.1111/ajt.13289

44. Huprikar S, Danziger-Isakov L AJ et al. Solid Organ Transplantation From Hepatitis B Virus-Positive Donors: Consensus Guidelines for Recipient Management. Am J Transplant. 2015;15:1162-1172.

45. Dhillon GS, Levitt J, Mallidi H, Valentine VG GM, D SRW. Impact of Hepatitis B Core Antibody Positive Donors in Lung and Heart-Lung Transplantation: An Analysis of the United Network for Organ Sharing Database. Transplantation. 2009;88:842-846.

46. Schlendorf KH, Zalawadiya S, Shah AS, Wigger M, Chung CY, Smith S, Danter M, Choi CW, Keebler ME, Brinkley DM, Sacks SB, Ooi H, Perri R, Awad JA, Lewis S, Hayes R, O’Dell H, Darragh C, Carver A, Edmonds C, 
Ruzevich-Scholl S LJ. Early outcomes using hepatitis C-positive donors for cardiac transplantation in the era of effective direct-acting anti-viral therapies. $J$ Hear Lung Transplant. 2018;37(6):763-769.

47. Strabelli TM, Siciliano RF, Vidal Campos S, Bianchi Castelli J, Bacal F, Bocchi EA U DE. Toxoplasma gondii Myocarditis after Adult Heart Transplantation: Successful Prophylaxis with Pyrimethamine. J Trop Med. 2012.

48. Dávila V1, Roncancio-Villamil G, Correa LA, Restrepo C, Madrid CA GJ. Disseminated toxoplasmosis in a heart transplant patient despite cotrimoxazole prophylaxis: A case report. Biomedica. 2017;37(3):303-307.

49. Chehrazi-Raffle A, Luu M, Yu Z, Liou F, Kittleson M, Hamilton M KJ. Toxoplasma gondii Serology and Outcomes After Heart Transplantation: Contention in the Literature. Transpl Proc. 2015;47(6):1949-1953.

50. Barge-Caballero E, Almenar-Bonet L, Crespo-Leiro MG, Brossa-Loidi V, Rangel-Sousa D, Gómez-Bueno M, Farrero-Torres M, Díaz-Molina B, Delgado-Jiménez J, Martínez-Sellés M, López-Granados A, De-la-FuenteGalán L, González-Costello J, Garrido-Bravo IP, Blasc G-VF. Preoperative Toxoplasma gondii serostatus does not affect long-term survival of cardiac transplant recipients. Analysis of the Spanish Heart Transplantation Registry. Int J Cardiol. 2018;250:183-187.

51. van Hellemond JJ, van Domburg RT, Caliskan K, Birim O BA. Toxoplasma gondii serostatus is not associated with impaired long-term survival after heart transplantation. Transplantation. 2013;96(12):1052-1058.

52. Brügemann J, Kampinga GA, Riezebos-Brilman A, et al. Two donor-related infections in a heart transplant recipient: one common, the other a tropical surprise. J Heart Lung Transplant. 2010;29(12):1433-1437. doi:10.1016/j.healun.2010.08.002

53. Gómez-Junyent J, Paredes-Zapata D, de las Parras ER, González-Costello J, Ruiz-Arranz Á, Cañizares R, Saugar JM MJ. Real-Time Polymerase Chain Reaction in Stool Detects Transmission of Strongyloides stercoralis from an Infected Donor to Solid Organ Transplant Recipients. Am J Trop Med Hyg. 2016;94(4):897-899.

54. Le M, Ravin K, Hasan A, Clauss H, Muchant DG, Pasko JK, Cipollina G, Abanyie F, Montgomery SP, Loy M, Ahmed M, Mathur M, Chokkalingam 
Mani B, Mehr J, Kotru A, Varma C, Maksimak M, Schultz M, Obradovic G, Alvarez R, Toyoda Y, Birkenbach M, Brunner E NJ. Single donor-derived strongyloidiasis in three solid organ transplant recipients: case series and review of the literature. Am J Transpl. 2014;14(5):1199-1206.

55. Abanyie FA, Gray EB, Delli Carpini KW, Yanofsky A, McAuliffe I, Rana M, Chin-Hong PV, Barone CN, Davis JL, Montgomery SP HS. Donor-derived Strongyloides stercoralis infection in solid organ transplant recipients in the United States, 2009-2013. Am J Transpl. 2015;15(5):1369-1375.

56. Abanyie FA, Valice E, Delli Carpini KW, et al. Organ donor screening practices for Strongyloides stercoralis infection among US organ procurement organizations. Transpl Infect Dis. 2018;20(3):4-7. doi:10.1111/tid.12865

57. Gómez-Junyent J, Paredes D, Hurtado JC, et al. High seroprevalence of Strongyloides stercoralis among individuals from endemic areas considered for solid organ transplant donation: A retrospective serum-bank based study. PLoS Negl Trop Dis. 2018;12(11):1-6. doi:10.1371/journal.pntd.0007010

58. Chin-Hong P V., Schwartz BS, Bern C, et al. Screening and treatment of chagas disease in organ transplant recipients in the United States:

Recommendations from the chagas in transplant working group. Am $J$ Transplant. 2011;11(4):672-680. doi:10.1111/j.1600-6143.2011.03444.x

59. Montgomery S, Pinney S, Steurer F, et al. Donor-Derived Trypanosoma cruzi Infection in Solid Organ Recipients in the United States, 2001-2011. Am J Transplant. 2013;13(9):2418-2425. doi:10.1111/ajt.12340

60. Pinazo M-J, Tendero DT, Ussetti P, et al. Recommendations for management of Chagas disease in organ and hematopoietic tissue transplantation programs in nonendemic areas. Transplant Rev. 2011;25(3):91-101.

doi:10.1016/j.trre.2010.12.002

61. Sabé N, González-Costello J, Oriol I, Sánchez-Salado JC, Ortega S, Oliver E, Manito N CJ. Donor-transmitted malaria after heart transplant managed successfully with artesunate. Transpl Infect Dis. 2014;16(6):999-1002.

62. Lagunes L, Len O, Sandiumenge A, Martínez-Saez E, Pumarola T, Bodro M, Macías A, Silva JT, Nuvials FX, Charco R, Moreso F PT. Successful multiple organ donation after donor brain death due to Actinomyces israelii meningitis. Transpl Infect Dis. 2017;19(4).

63. Forest SJ, Friedmann P, Bello R, Goldstein DJ, Muggia V D DA. Cardiac 
transplantation from infected donors: is it safe. J Card Surg. 2015;30(3):288295.

64. Amdani SM, Du W, Aggarwal S. Outcome of pediatric heart transplantation in blood culture positive donors in the United States. Clin Transplant. 2018;32(5):e13249. doi:10.1111/ctr.13249

65. Galvão LM, Oliveira APR de, Ibanês AS, et al. Fatal case of donor-derived colistin-resistant carbapenemase-producing Klebsiella pneumoniae transmission in cardiac transplantation. Braz J Infect Dis. 22(3):235-238. doi:10.1016/j.bjid.2018.04.005

66. Ariza-Heredia EJ, Patel R, Blumberg EA, et al. Outcomes of transplantation using organs from a donor infected with Klebsiella pneumoniae carbapenemase (KPC)-producing K. pneumoniae. Transpl Infect Dis. 2012;14(3):229-236. doi:10.1111/j.1399-3062.2012.00742.x

67. Weile J, Eickmeyer H, Dreier J, et al. First case of Mycobacterium tuberculosis transmission by heart transplantation from donor to recipient. Int $J$ Med Microbiol. 2013;303(8):449-451. doi:10.1016/j.ijmm.2013.06.005

68. Abad CLR, Razonable RR. Donor derived Mycobacterium tuberculosis infection after solid-organ transplantation: A comprehensive review. Transpl Infect Dis. 2018;20(5):e12971. doi:10.1111/tid.12971

69. Nelson JK, Giraldeau G, Montoya JG, Deresinski S, Ho DY, Pham M. DonorDerived Coccidioides immitis Endocarditis and Disseminated Infection in the Setting of Solid Organ Transplantation. Open forum Infect Dis. 2016;3(3):ofw086. doi:10.1093/ofid/ofw086

70. Kim S-H, Ha YE, Youn J-C, et al. Fatal scedosporiosis in multiple solid organ allografts transmitted from a nearly-drowned donor. Am J Transplant. 2015;15(3):833-840. doi:10.1111/ajt.13008

71. Sun H-Y, Alexander BD, Lortholary O, et al. Unrecognized pretransplant and donor-derived cryptococcal disease in organ transplant recipients. Clin Infect Dis. 2010;51(9):1062-1069. doi:10.1086/656584

72. Blodget E, Geiseler PJ, Larsen RA, Stapfer M, Qazi Y, Petrovic LM. Donorderived Coccidioides immitis fungemia in solid organ transplant recipients. Transpl Infect Dis. 2012;14(3):305-310. doi:10.1111/j.13993062.2011.00698.x

73. Dierberg KL, Marr KA, Subramanian A, et al. Donor-derived organ transplant 
transmission of coccidioidomycosis. Transpl Infect Dis. 2012;14(3):300-304. doi:10.1111/j.1399-3062.2011.00696.x

74. Kusne S, Taranto S, Covington S, et al. Coccidioidomycosis Transmission Through Organ Transplantation: A Report of the OPTN Ad Hoc Disease Transmission Advisory Committee. Am J Transplant. 2016;16(12):3562-3567. doi:10.1111/ajt.13950

75. Rosso F, Pineda JC, Sanz AM, Cedano JA C LA. Transmission of dengue virus from deceased donors to solid organ transplant recipients: Case report and literature review. Brazilian J Infect Dis. 2018;22(1):63-69.

76. Winston DJ, Vikram HR, Rabe IB, et al. Donor-derived West Nile virus infection in solid organ transplant recipients: report of four additional cases and review of clinical, diagnostic, and therapeutic features. Transplantation. 2014;97(9):881-889. doi:10.1097/TP.0000000000000024

77. Simkins J, Anjan S, Morillas-Rodriguez JA, et al. Screening for Zika virus in deceased organ donors in Florida. Am J Transplant. 2018;18(3):731-736. doi:10.1111/ajt.14582

78. Farnon EC, Kokko KE, Budge PJ, et al. Transmission of Balamuthia mandrillaris by Organ Transplantation. Clin Infect Dis. 2016;63(7):878-888. doi:10.1093/cid/ciw422

79. Kaul DR, Covington S, Taranto S, et al. Solid organ transplant donors with central nervous system infection. Transplantation. 2014;98(6):666-670. doi:10.1097/TP.0000000000000117

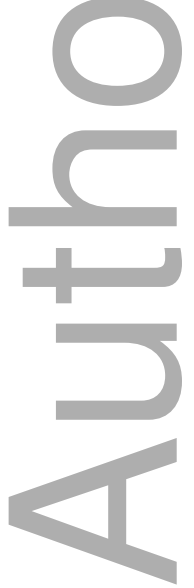




\section{University Library}

\section{- M M N E R VA A gateway to Melbourne's research publications}

Minerva Access is the Institutional Repository of The University of Melbourne

\section{Author/s:}

Conway, J;Ballweg, JA;Fenton, M;Kindel, S;Chrisant, M;Weintraub, RG;Danziger-Isakov, L;Kirk, R;Meira, O;Davies, RR;Dipchand, Al

Title:

Review of the impact of donor characteristics on pediatric heart transplant outcomes

Date:

2020-03-21

\section{Citation:}

Conway, J., Ballweg, J. A., Fenton, M., Kindel, S., Chrisant, M., Weintraub, R. G., DanzigerIsakov, L., Kirk, R., Meira, O., Davies, R. R. \& Dipchand, A. I. (2020). Review of the impact of donor characteristics on pediatric heart transplant outcomes. Pediatric Transplantation, 24 (3), https://doi.org/10.1111/petr.13680.

Persistent Link:

http://hdl.handle.net/11343/275558 